Military Technical College Kobry El-Kobbah, Cairo, Egypt.

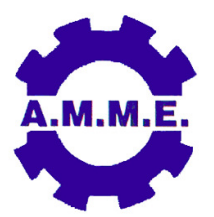

$17^{\text {th }}$ International Conference on Applied Mechanics and

Mechanical Engineering.

\title{
STUDY OF AN ENGINE MONITORING SYSTEM FOR PLUG-IN SERIES HYBRID ELECTRIC SCOOTERS
}

\author{
K. L. Kuo*

\section{ABSTRACT}

Currently, commercially available electric scooters often have problems such as insufficient cruising endurance, overly lengthy charging time, and imperfect charging facilities. Therefore, to enhance their cruising endurance, this study took a commercially available gasoline scooter as an experimental vehicle development platform and used a $48 \mathrm{~V} / 23.65 \mathrm{Ah}$ lithium battery as one of its power sources in tandem with the automotive generator driven by the fuel engine as another power source to drive a $1.5 \mathrm{~kW}$ brushless direct current motor. Through the series engine monitoring system as well as the power and signal integration system developed in this study, the scooter becomes a dual power system that can improve the traveling mileage effect. In this study, we used LabVIEW, the graphic-based programming language, and its embedded systems for the control and monitoring system, to develop the signal measurement and control for monitoring and controlling the experimental vehicle status; as well as to analyze the power consumption data of the lithium battery, generator, and motor, and the effect of actual vehicle validation. Finally, via the chassis dynamometer of this series hybrid electric scooter, a performance test of the electric scooter was conducted. Under the single power mode of generator, the generator supplies the power output to the motor at all times; at a constant speed of $20 \mathrm{~km} / \mathrm{h}$, the fuel consumption was $13.67 \mathrm{~km} / \mathrm{L}$, the electric energy converted from the fuel was $1285.48 \mathrm{~kJ} / \mathrm{L}$. Under the dual power mode of generator, the fuel consumption was $17.65 \mathrm{~km} / \mathrm{L}$, the electric energy converted from the fuel was $1684.44 \mathrm{~kJ} / \mathrm{L}$.

KEYWORDS: Engine monitoring system, plug-in series, dual power system, start-stop system

* Associate Professor, Dept. of Vehicle Engineering, National Taipei University of Technology, Taipei Taiwan. 


\section{INTRODUCTION}

This study takes "the technology of an electric vehicle with a plug-in series hybrid drive system" as the research direction and hopes to integrate the advantages of electric scooters, such as having good low-speed performance, high operating efficiency, and low emissions, with the advantages of gasoline scooters, such as fast energy refueling (refueling time) and complete energy refueling facilities (gas station facilities) [1]. The series hybrid drive system proposed by this study is worthy of application to the research relating to electric vehicles travelling in urban areas.

\section{ARCHITECTURE OF THE SERIES HYBRID ELECTRIC SCOOTER SYSTEM}

For the series scooter of this study, we added an automotive generator to a commercially available YAMAHA scooter - CUXI 100, as shown in Fig. 1. It provides a power source to the electric motor when the battery power is insufficient [2]. In addition, we equipped a brushless direct current motor and a lithium battery as the main output power source. Subsequently, for the control, signal measurement, and data computing of each system, we used the embedded systems for monitoring and control ( $\mathrm{NI}$ cRIO-9022 controller and $\mathrm{NI}$ cRIO-9118 chassis), produced by the American company, National Instruments $(\mathrm{NI})$ and the real-time monitoring module constructed on the graphical programming design platform, LabVIEW. The following introduces the three major system architectures of this study: (1) Engine generator module; (2) Electric vehicle system architecture; (3) Real-time monitoring system. The engine generator module is shown in Fig. 2(a); the electric vehicle system architecture is shown in Fig. 2 (b).

\section{Engine Generator Module}

This architecture allows the engine to operate in the optimum efficiency region easily, and separates the engine and the driving wheels. When the battery power is sufficient, without the need to start up the engine, the vehicle can operate and travel in a similar way to an electric car without emitting exhaust gases and $\mathrm{CO}_{2}$. Under the complementarity of the real-time monitoring system, the engine start-stop function can be achieved within a certain range of the state of charge (SOC) of the battery, reducing the decline in air quality caused by emissions and the accumulation of exhaust gases emissions in the intersection. 


\section{Architecture of Electric Vehicle System}

In this study, as the basic architecture of the experimental vehicle is a typical gasoline scooter, it is therefore necessary to add a generator, DC brushless motor and a battery pack as the electric vehicle architecture, as shown in Fig. 3. In order for the DC current to become the kinetic energy output of the series hybrid drive scooter, this study adopted a brushless direct current motor and a $48 \mathrm{~V}$ lithium battery as the power source in the electric vehicle system.

\section{Real-Time Monitoring System}

As the actual vehicle cannot operate using the utility power (AC 110V) and desktop computers in the laboratory for data acquisition, analytical computing, and control, this study chose an embedded system for monitoring and control that can use the direct current power as the engine control unit (ECU) to complete the aforementioned tasks, as shown in Fig. 4 [3]. In conjunction with the use of a portable wireless access point (AP), human-machine interfaces with portable devices (notebook and tablets computers, etc.) were established to communicate with the ECU, as shown in Fig. 5.

\section{DESIGN AND IMPLEMENTATION OF THE ENGUNE MONITORING SYSTEM}

In this study, we used a commercially available gasoline scooter and used its engine output terminal to drive an automotive generator as one of the power sources for the electric vehicle. As the generator is driven by the engine, the time to operate the generator function would need to control the engine output. The advantage of the series hybrid architecture is that this design can allow the engine to operate for only a single task and can also obtain stable kinetic energy output; therefore, compared with other hybrid drive forms, the engine in the series hybrid drive system is easier to operate in the optimum efficiency range. While the throttle position sensor (TPS) is also a very important sensor, the TPS can learn whether the engine is in an idling state and the riders will use the required driving force to rotate the throttle valve's opening from the throttle grip through the steel cable. At this point of time, the TPS will also give the corresponding voltage of the opening to the computer via feedback as one of the output references, as shown in Fig. 6.

In this study, to accomplish the objectives of the start-stop function of this experimental vehicle, it is necessary to understand the circuit of the original scooter 
and then modify it, so that the engine start-up and shut-down are changed from the original manual control to as controlled by the CompactRIO.

\section{Control of Engine's Rotational Speed}

The advantages of in series hybrid driving architecture is that the kinetic energy of the engine output is only for the purpose of power generation, so it is easy to operate the engine in the optimum efficiency region. In this study, we mainly controlled the engine at the assigned rotational speed, so that the engine was operating in the optimum efficiency region. Hall Sensor in engine right side as shown in Fig. 7. The rotational speed of the engine was originally operated by a manual throttle grip, and then the opening of throttle valve was adjusted through the interlocking steel cable in the rear of throttle grip. In this study, we implemented the CompactRIO to control the engine's rotational speed, to control the stepper motor and the driver CD-2D24MB, so that the engine is operating within a range of specific rotational speeds [4]. The acquisition card on the CompactRIO acquires the input signals of the rotational speed sensor and throttle position sensor of the engine. After computation by the software written for this study, the real-time rotational speeds of the engine are obtained. Compared to the assigned target value, the error of the rotational speed of the engine is set as the input. As for the error value, CompactRIO again computes the TPS's target value and the actual TPS value for comparison. These output signals are sent to the engine monitoring board to amplify the signals and control the stepper motor. The control diagram for the rotational speed of the engine is shown in Fig. 8. Finally, based on the comparison between the present TPS value and the TPS's target value, if the difference is higher than the permissible error value of the TPS, the stepper motor will be actuated in a counter clockwise direction; if it is less than the permissible error value of the TPS, the stepper motor will be actuated in a clockwise direction [5].

\section{Engine Monitoring Board}

The engine monitoring system architecture diagram as planned in this study is shown in Fig. 9 and Fig. 10. The main function of the system is to amplify the output signals of CompactRIO and supply the stepper motor and the rotational speed sensor power supply of the engine to be integrated into the circuit board; the signals of the rotational speed sensor of the engine are also sent back to the CompactRIO. The components on the board include relays, transistors, a buck converter module, boost converter module, and unidirectional diodes. 


\section{DESIGN AND IMPLEMENTATION OF THE ENTIRE VEHICLE SYSTEMS INTERGRETION}

\section{Series Hybrid Electric Scooter System}

In this study, the engine output driving force of a gasoline scooter was modified to be electric output; then the automotive generator was driven by the output shaft of the original engine so it was the power source of the power generation system. Figure 11 (left) shows the original power transmission configuration; Figure 11 (right) shows the power transmission configuration for the series hybrid drive scooter of this study.

\section{Power and Signal Integration System}

In this study, the power and the signals of the experimental vehicle include the related signals used by the rider (output power control and constant speed control), the real-time voltage, and current signal acquired values for the battery and the generator when the vehicle was traveling, as well as the engine's rotational speeds and throttle valve. The aforementioned information provides the calibration of the acquisition value of the apparatus when it was being developed, or provides the real-time information when driving, as well as the voltages of the related apparatus (motor, engine) for controlling the experimental vehicle. The power signals of the entire vehicle are shown in Fig. 12.

\section{Experimental Apparatus and Experimental Vehicle Configuration}

Figure 13 is the hardware configuration diagram for the whole vehicle. In order to ensure the best use of space on the experimental vehicle, the whole vehicle is divided into four parts: the first part is the interior region of the front inclined plate of the scooter, as illustrated in Fig. 14; the second part is the power transmission region (the region that was originally for the continuously variable transmission, CVT); the third part is the interior region of the storage of the scooter, as illustrated in Fig. 15; the fourth part is the rear rack region, as illustrated in Fig. 16.

\section{RESULTS AND DISCUSSIONS ON THE EXPERIMENTAL CAR TEST RESULTS}

\section{Single Power Generator and Fuel Consumption Experiment}

The aim of the following test is to validate the scenario when the lithium battery power 
level is insufficient, in which the engine and the generator were used as the lone power source for the motor. Before and after the experiment, the experimental fuel tank was weighed; subtracting the obtained weights resulted in the weight of fuel consumed. In addition to the fuel consumption, the traveling distance through the overall course of the experiment is still required. Figure 17 show the plots for the single power generator test results at a constant speed of $20 \mathrm{~km} / \mathrm{h}$. During the experiment at a constant speed of $20 \mathrm{~km} / \mathrm{h}$, a total $155.6 \mathrm{~g}$ of unleaded gasoline with a research octane number (RON) of 92 was consumed; the total traveling distance was approximately 2.85 kilometers; the total power consumption by motor was $267.76 \mathrm{~kJ}$. Through the conversion equation, the fuel consumption performances were $13.67 \mathrm{~km} / \mathrm{L}$ and $1285.48 \mathrm{~kJ} / \mathrm{L}$.

\section{Dual Power Strategy Validation and Fuel Consumption Test}

In this experiment, the vehicle travelled at a constant speed of $20 \mathrm{~km} / \mathrm{h}$. SOC $\mathrm{H}$ and SOC $L$ were set to be $50.5 \%$ and $49.5 \%$. The lithium battery capacity adopted in this study was $48 \mathrm{~V} / 23.65 \mathrm{Ah}$. For the SOC through the experimental process, every $1 \%$ was $851.4 \mathrm{AS}(0.2365 \mathrm{Ah})$ under these conditions, not taking the aging of the battery into consideration. Figure 18 shows the plots for the dual power test results at a constant speed of $20 \mathrm{~km} / \mathrm{h}$. Through with the experimental process, a total of $132.8 \mathrm{~g}$ of the unleaded gasoline with RON 92 was consumed; the total traveling distance was 3.14 kilometer, each liter of fuel can allow a travel distance of $17.65 \mathrm{~km}$ in terms of fuel consumption. The total power consumption for the motor was $299.46 \mathrm{~kJ}$ and each liter can provide the motor with a fuel consumption of $1684.44 \mathrm{~kJ}$.

\section{CONCLUSIONS}

1. The power and signal integration system developed in this study integrates the two powers of the power generator and lithium battery, providing power supply to devices with different voltages. The system converts the voltage and current parameters of the lithium battery, generator, and brushless direct current motor into voltage signals to be sent to the engine control unit. After integration with the engine monitoring system, the voltages are displayed on the real-time monitoring and control screen, so that researchers can understand the real-time operation situations of the experimental vehicle. After analyzing the data record and further understanding the experiment process, the power and the SOC of lithium battery, generator, brushless direct current motor. 
2. Using a chassis dynamometer, the experimental vehicle was subjected to tests on electric scooter performance, which analyzed the single power and dual power operations. The data was analyzed and discussed. The single power experiment validated that the generator could still drive the vehicle; the fuel consumption at $20 \mathrm{~km} / \mathrm{h}$ was $13.67 \mathrm{~km} / \mathrm{L}$. In the dual power experiment, the lithium battery was used as a balance, at $20 \mathrm{~km} / \mathrm{h}$ fuel consumption was $17.65 \mathrm{~km} / \mathrm{L}$.

3. As revealed by the experimental results, for the fuel consumption of the actual vehicle with single power and dual power, in both cases the increase rate of fuel consumption found by converting the traveling distance or the energy provided to the motor, gave a comparative increase rate between single power and dual power at a constant speed of $20 \mathrm{~km} / \mathrm{h}$ of about $30 \%$.If for other driving speed, the results may be different.

4. When the generator was in single power operation, the energy was similar to that provided by the general gasoline scooter, which is required to keep the vehicle running on demand; while excess energy will be lost. On the other hand, the dual power operation had the balance of the lithium battery, the excessive power could be stored in the battery; when it lacks power, it can be supplemented by the battery; during deceleration, the energy from motor braking can be recovered and stored in the battery, which further improves the fuel consumption performance.

\section{ACKNOWLEDGEMENT}

This research is partially supported by Ministry of Science and Technology, Taiwan, ROC, under contract MOST104-2221-E-027-113.

\section{REFERENCES}

[1] J. L. Shang and B. G. Pollet, "Hydrogen fuel cell hybrid scooter (HFCHS) with plug-in features on Birmingham campus," Int. J. of Hydrogen Energy, Vol. 35, Issue 23, pp. 12709-12715 (2010).

[2] W. Xiong, Y. Zhang and C. Yin, "Optimal energy management for a series-parallel hybrid electric bus", Energy Conversion and Management, Vol. 50, pp. 1730-1738 (2009).

[3] National Instruments Taiwan, http://taiwan.ni.com/.

[4] Cheng Den Enterprise Co., Ltd., http://www.chyenden.com.tw/.

[5] CPC Corporation, Taiwan ,http://cpc.demosite.tw/division/rb/product.aspx. 


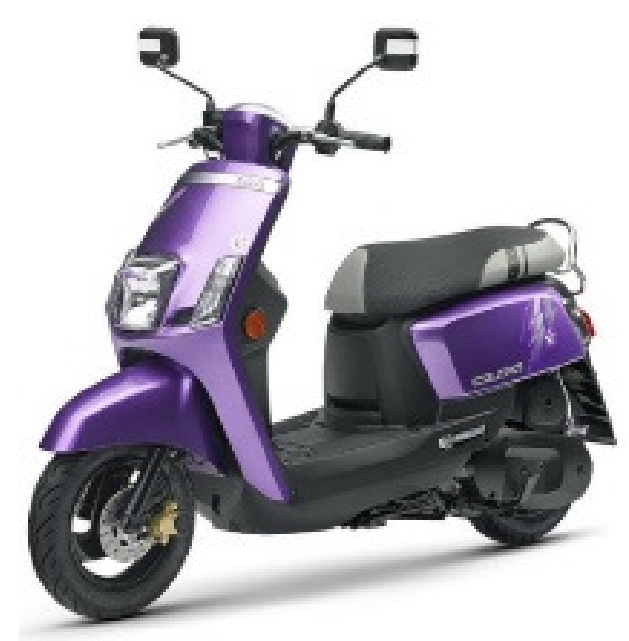

Fig. 1. Gasoline scooter (CUXI).

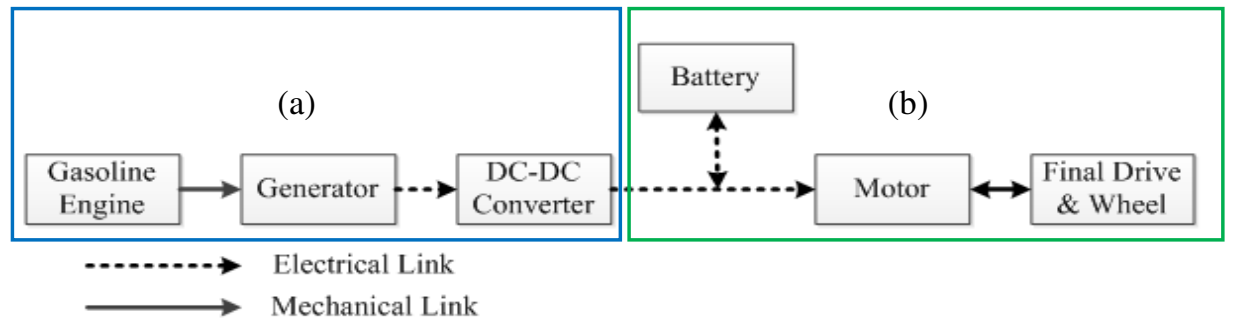

Fig. 2. Series hybrid drive electric vehicle system architecture.

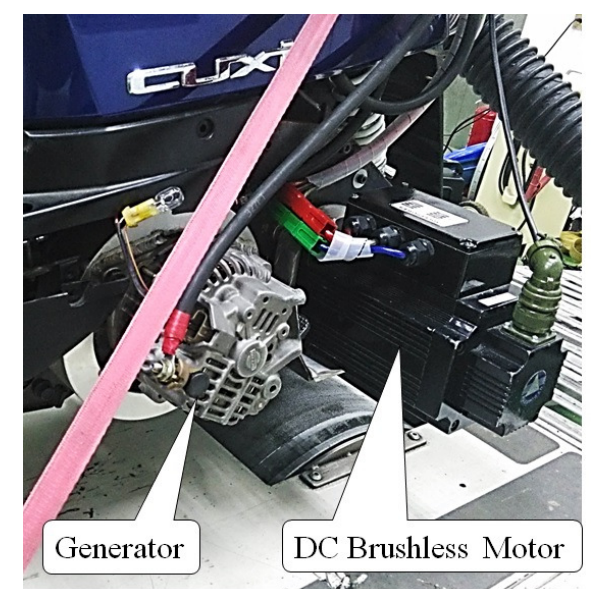

Fig. 3. Generator and DC brushless motor. 

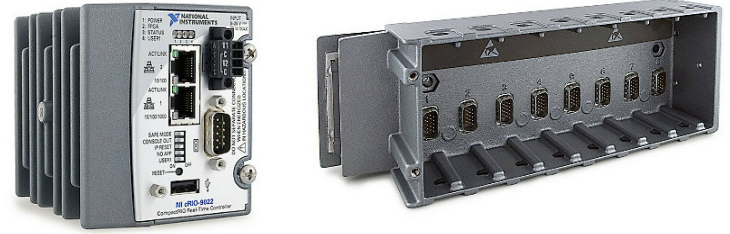

Fig. 4. Entities of embedded systems for monitoring and control [3].

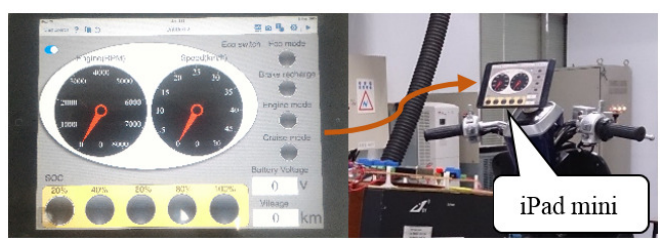

Fig. 5. Real-time monitoring screen and placement of iPad mini.

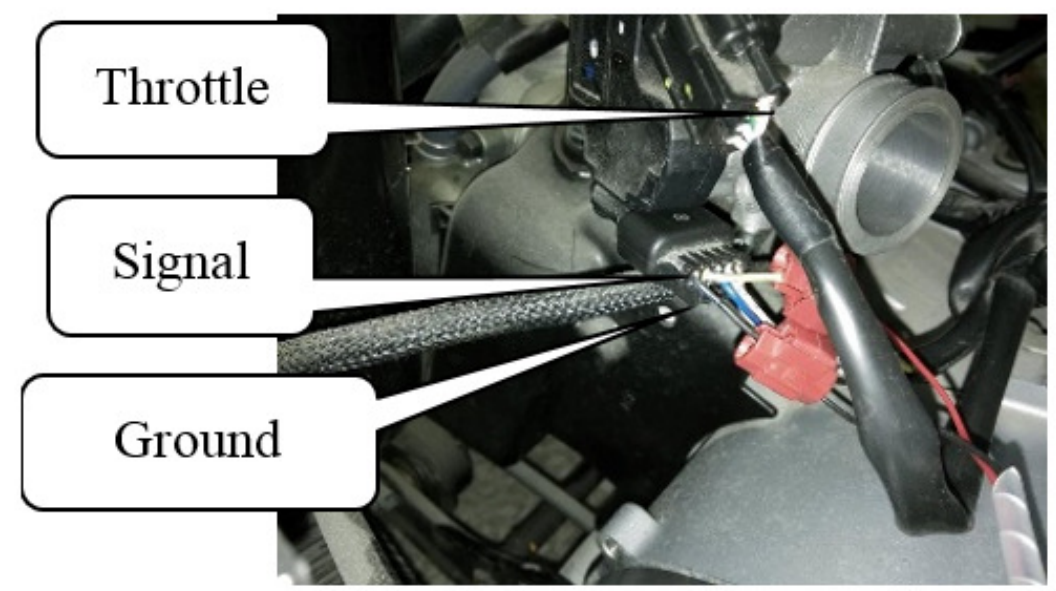

Fig. 6. TPS acquisition in actual vehicle.

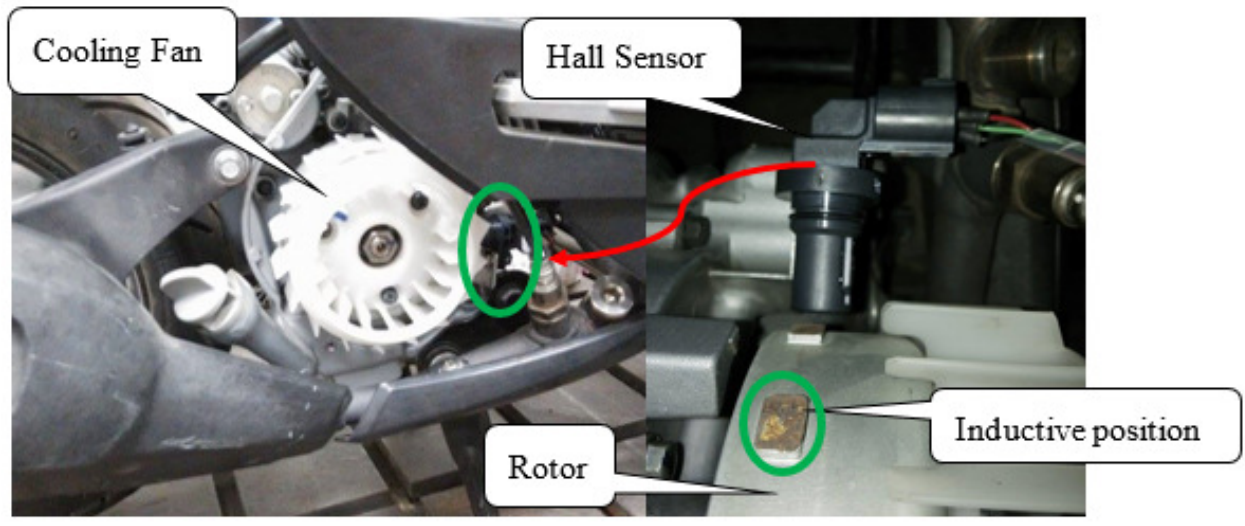

Fig. 7. Hall Sensor in engine right side. 


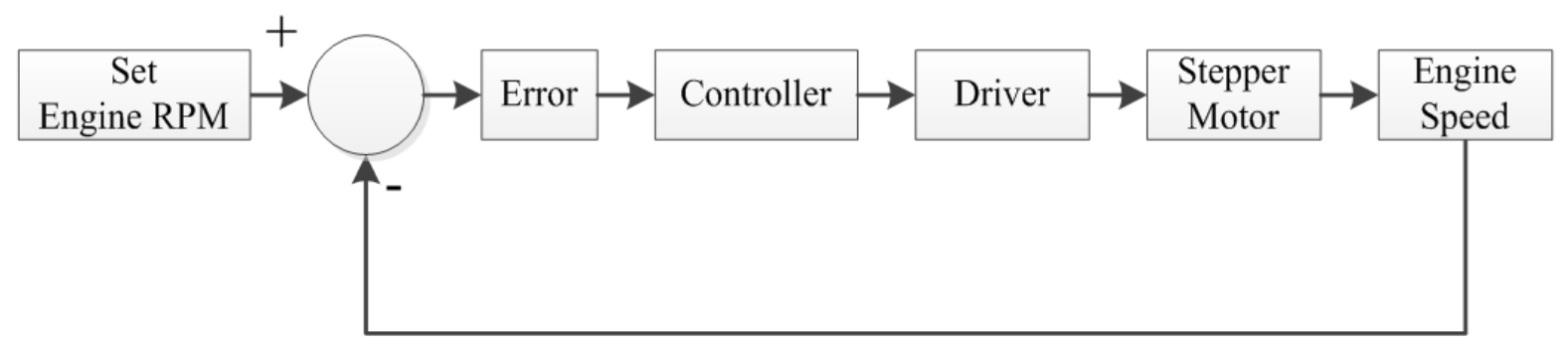

Fig. 8. Control diagram for the rotational speed of the engine.

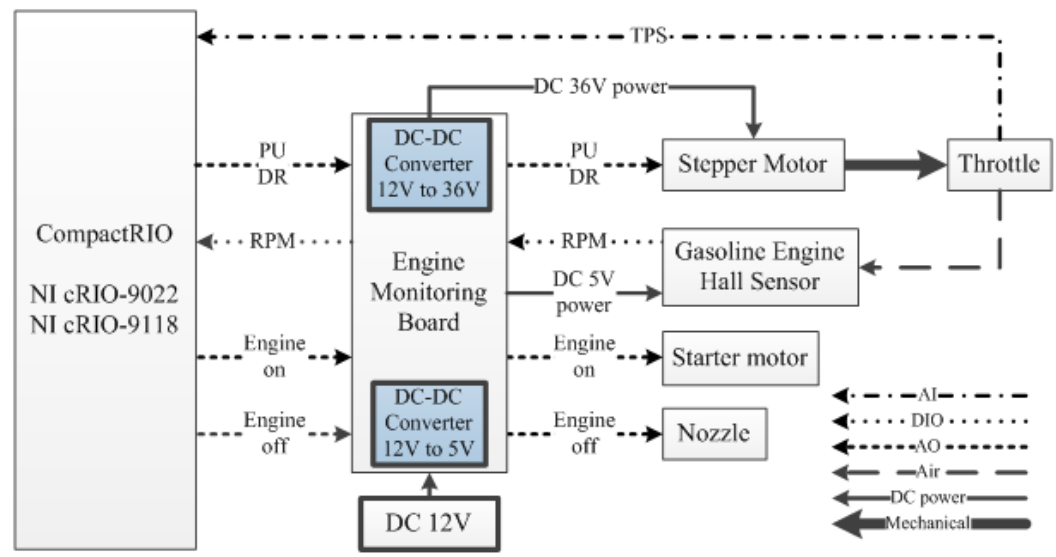

Fig. 9. Engine Monitoring System Architecture.

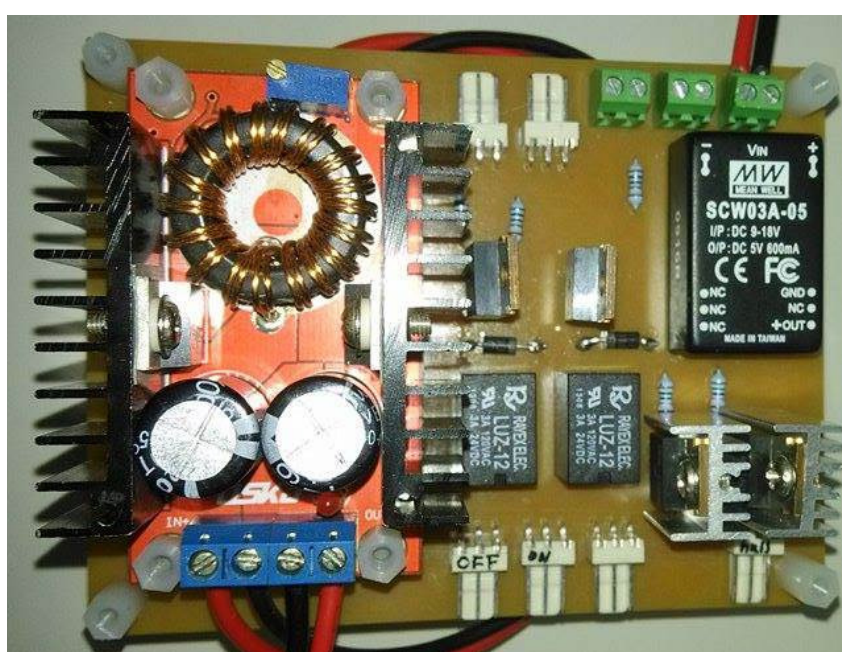

Fig. 10. Entities of engine monitoring system. 

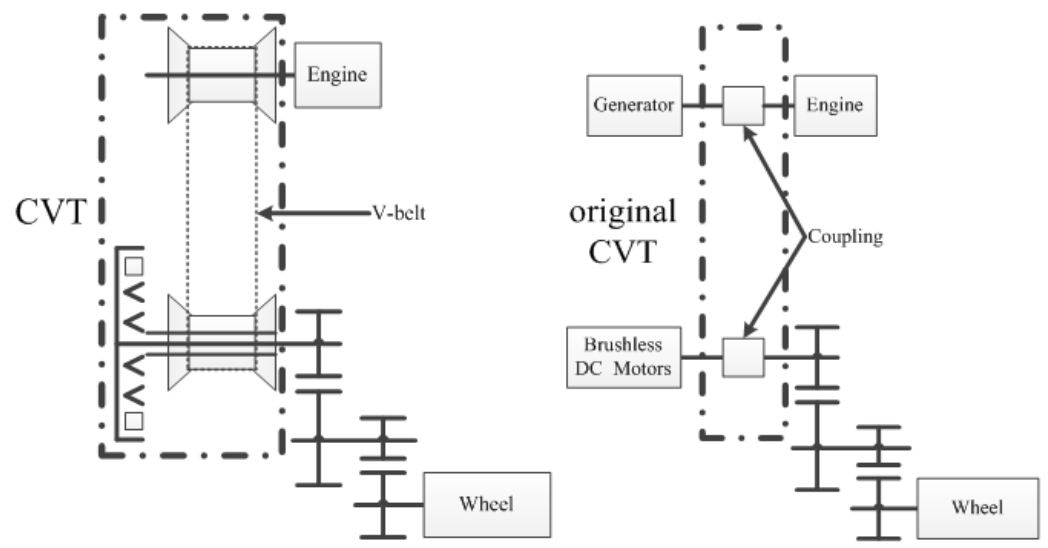

Fig. 11. Power transmission configurations (left: original; right: series).

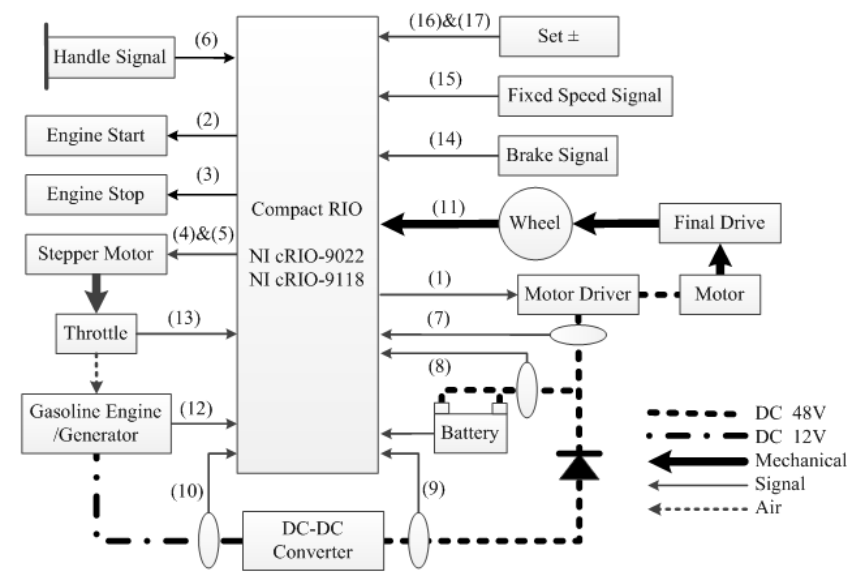

Fig. 12. Entire vehicle's power signal integration.

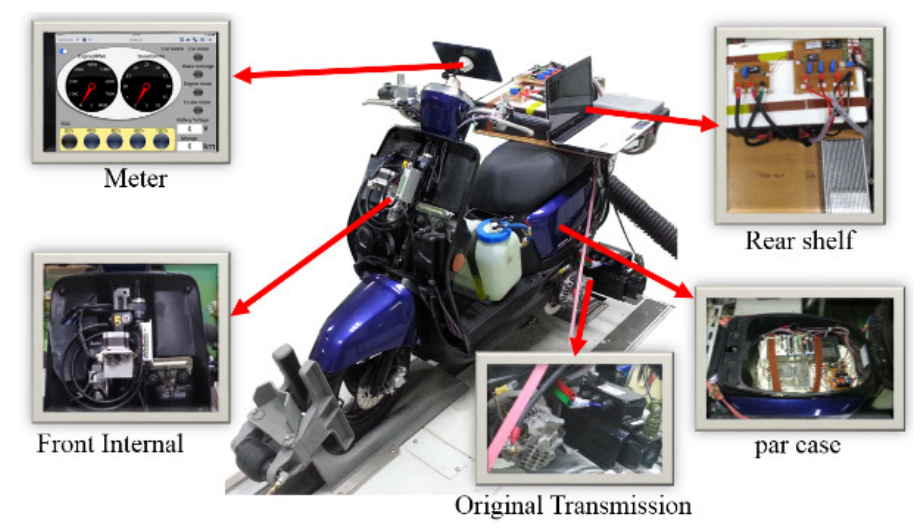

Fig. 13. Hardware configuration diagram of the whole vehicle. 


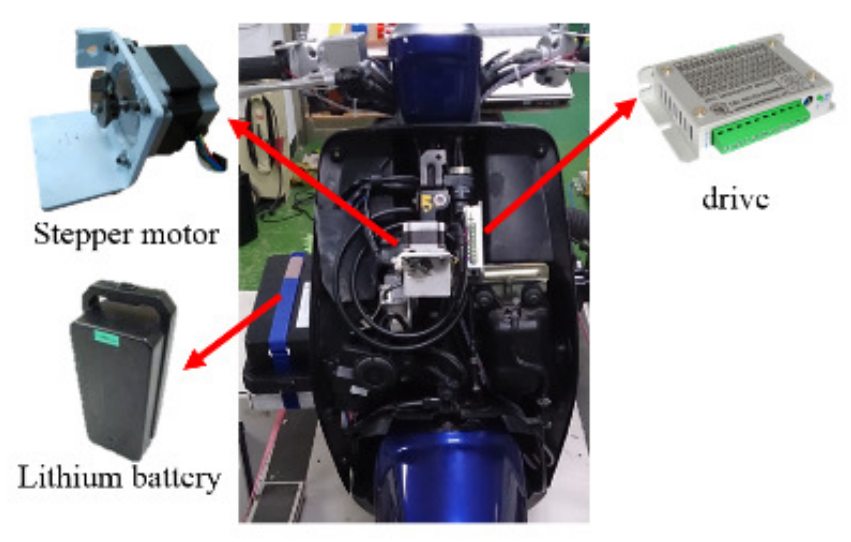

Fig. 14. Front inclined plate, interior region.

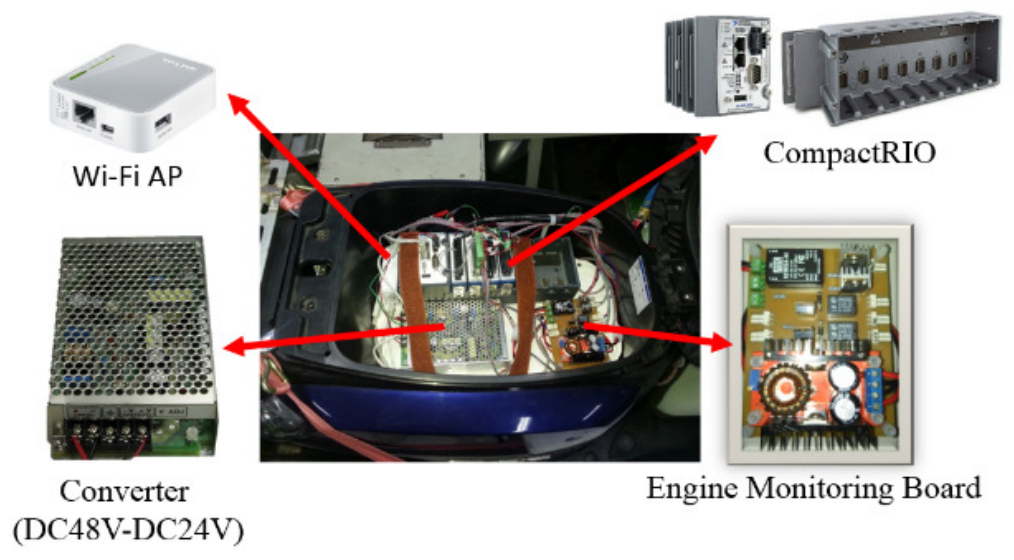

Fig. 15. Underseat storage region of the scooter.

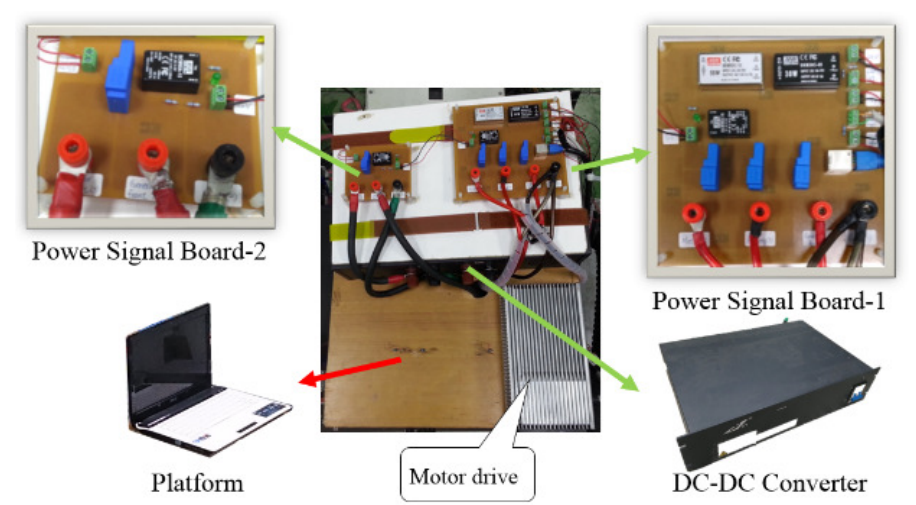

Fig. 16. Rear rack region. 


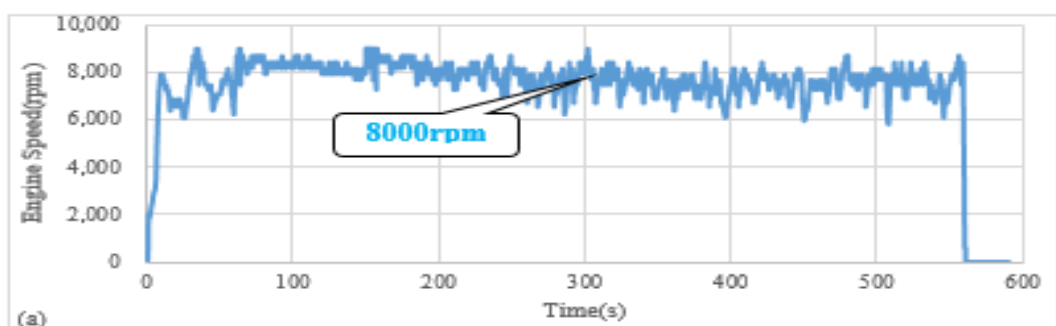

(a)
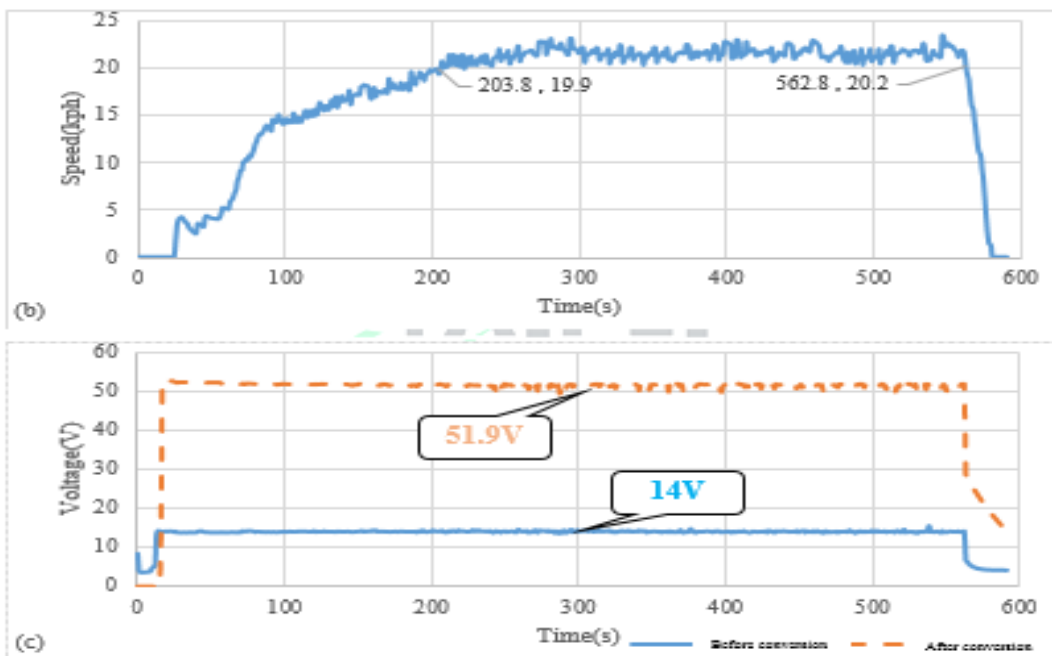

(c)
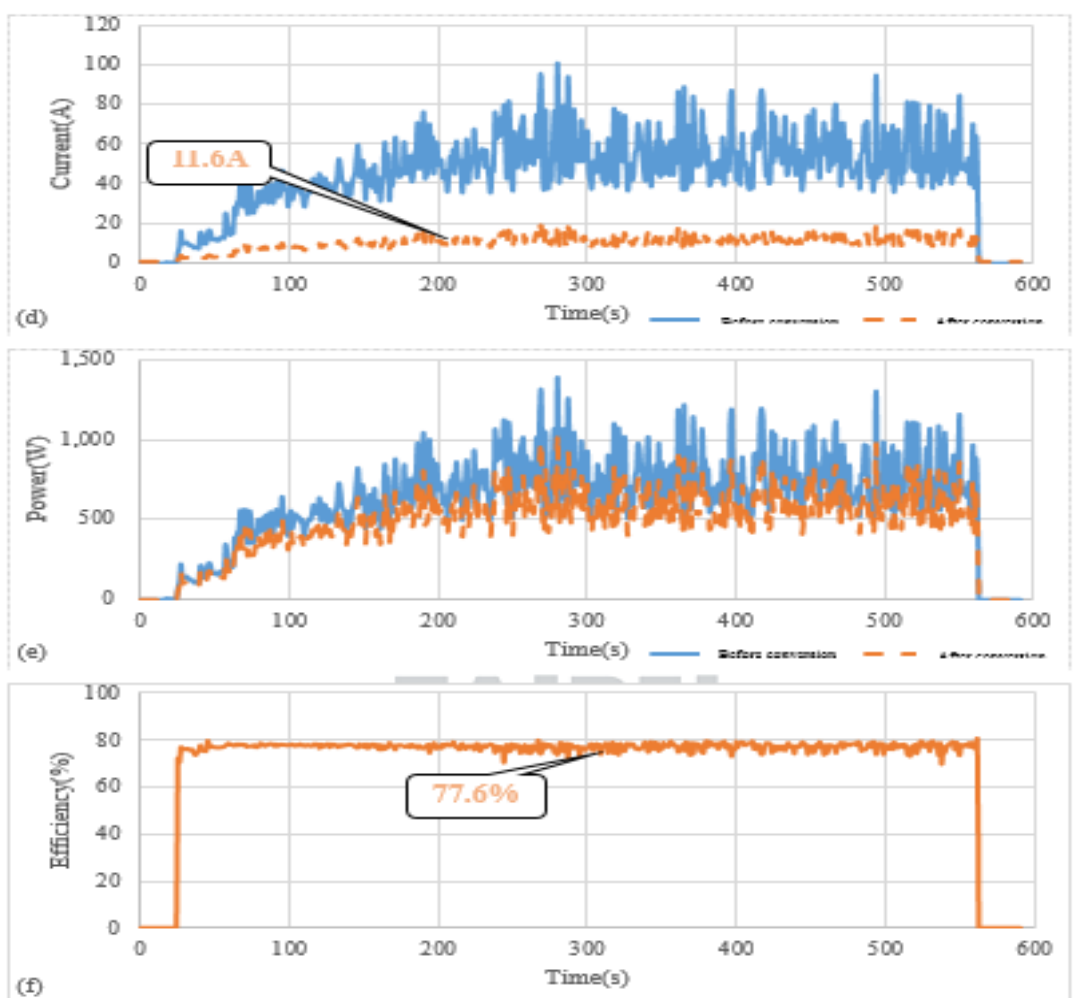

Fig. 17. Plots for the single power generator test results at constant speed of $20 \mathrm{~km} / \mathrm{h}$. 

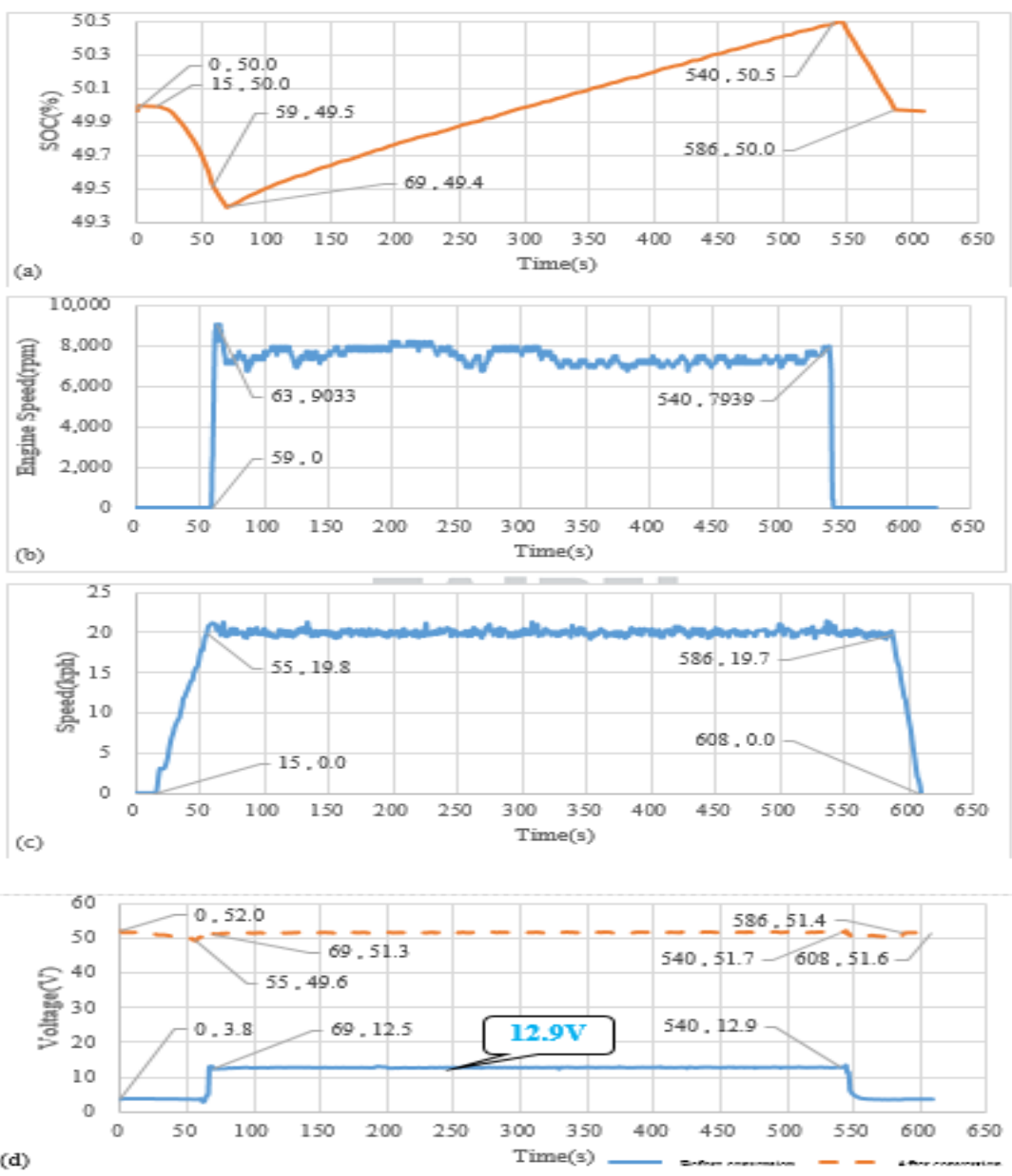

(d)

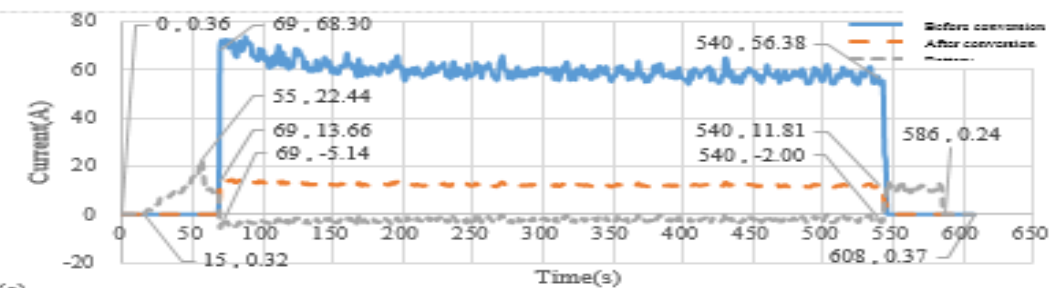

(e)

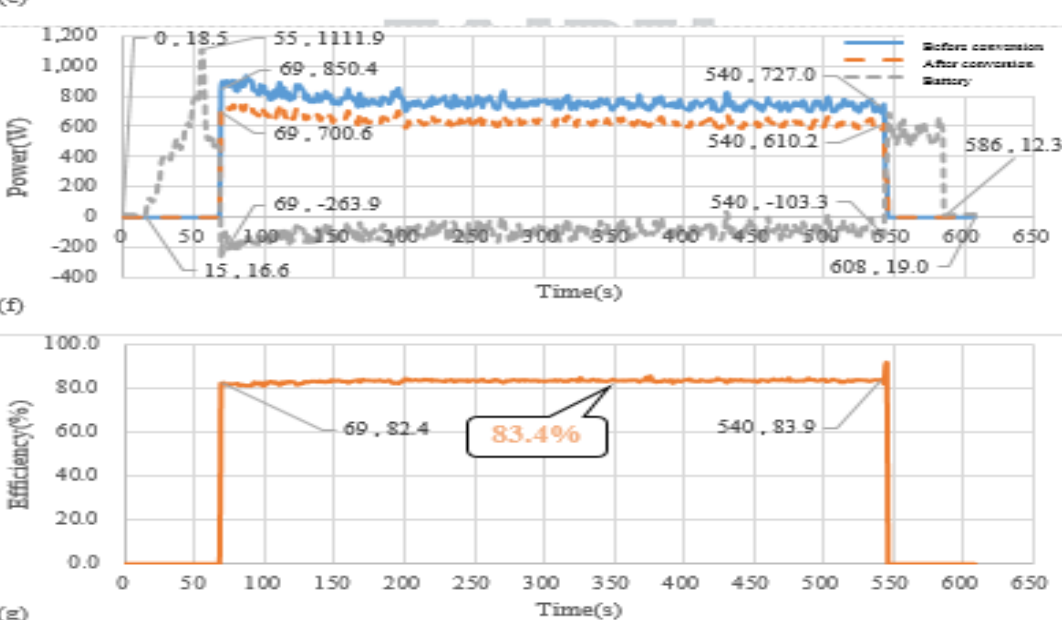

Fig. 18. Plots for dual power test results at constant speed of $20 \mathrm{~km} / \mathrm{h}$. 